\title{
Multisystem Langerhans Cell Histiocytosis with Fatal Outcome in Adult Patient: A Case Report
}

\author{
Veljko Flego ${ }^{1,}$, Darian Volaric ${ }^{2}$ \\ ${ }^{1}$ Department of Pulmonology, Clinical Hospital Centre Rijeka, Rijeka, Croatia \\ ${ }^{2}$ Primary Health Care Office, Health Centre of Primorsko-Goranska County, Rijeka, Croatia
}

Email address:

veljko.flego@medri.uniri.hr (V. Flego),darian.volaric7@gmail.com (D. Volaric)

${ }^{*}$ Corresponding author

\section{To cite this article:}

Veljko Flego, Darian Volaric. Multisystem Langerhans Cell Histiocytosis with Fatal Outcome in Adult Patient: A Case Report. Clinical Medicine Research. Vol. 6, No. 4, 2017, pp. 139-142. doi: 10.11648/j.cmr.20170604.15

Received: May 21, 2017; Accepted: June 28, 2017; Published: July 26, 2017

\begin{abstract}
Langerhans cell histiocytosis $(\mathrm{LCH})$ is a rare disorder characterized by abnormal proliferation of cells with a Langerhans cell phenotype, which comprises a wide range of clinical presentations. The reported patient is a 55-year old female with multy-sistem LCH and pulmonary tuberculosis. During diagnostic processing, infiltrates of Langerhans cells (S$100+, \mathrm{CD} 1 \mathrm{a}+$ ) in the epidermis, intestinal mucosa and bone marrow, were discovered. Transbronchial needle biopsy of the lung revealed non-specific clusters of macrophages (CD68+, CD1a-). Although CD1a was negative, positive CD68, thoracic MSCT and clinical findings indicated pulmonary LCH. Corticosteroid treatment led to significant clinical improvement. Seven months after treatment with corticosteroids the patient developed a spontaneous left-sided pneumothorax. Thoracic HR (high resolution)-MSCT was highly suggestive for active Mycobacterium tuberculosis (MT) infection together with the positive QUANTIFERON-TB test and typical symptoms. One week after starting standard triple antituberculotic therapy the patient developed hypovolemic shock. Despite all medical efforts, the patient died on the thirteenth day of intensive treatment for multiple organ failure.
\end{abstract}

Keywords: Langerhans-Cell Histiocytosis, Pulmonary Tuberculosis, Multislice Computed Tomography, Corticosteroids, Multiple Organ Failure

\section{Introduction}

Langerhans cell histiocytosis (LCH) is a rare disorder characterized by abnormal proliferation of cells with a Langerhans cell phenotype, which comprises a wide range of clinical presentations. LCH contains some of the elements of both a neoplastic process and a reactive immune disorder, but the etiology of the lesion is still elusive. LCH was historically divided into three clinical entities based on extent of tissue involvement and severity of presentation. These three entities were eosinophilic granuloma, Hand-SchulerChristian disease and Letterer-Siwe disease. Due to similarities of their histologic appearance, they were grouped together under the term histiocytosis $\mathrm{X}$. This term was recently changed to $\mathrm{LCH}$, emphasizing the primary cell involved in the disease process [1]. The clinical presentation of LCH varies from clinically trivial lesions that resolve spontaneously to life-threatening disseminated disease that require systemic chemotherapy and, in some cases, hematopoietic stem cell transplantation [2].

The estimated incidence in adults is about 1-2 cases per milion and is lower than that in children. Diagnosis of LCH is difficult and may be delayed due to its rarity and wide clinical manifestation.

\section{Case Presentation}

A 55-year-old female patient presented with occasional dyspnea, weakness, diarrhea, fever, leg edema and eczematous skin lesions of the torso.

The patient's physical examination revealed silent breathing sounds on both sides of the chest, pretibial edema on both legs, pale skin and the presentation of a erythematosus-papular skin rash on the neck, torso and below her breasts. 
Past illnesses included uterine mioma operation 15 years ago and acute pancreatitis 20 years ago.

The pathological results of laboratory tests on hospital admission included: red blood cell count (RBC): $3.64 \times 10^{12} / \mathrm{L}$ (reference interval: $3.86-5.08) \times 10^{12} / \mathrm{L}$, hemoglobin: $102 \mathrm{~g} / \mathrm{L}$ (reference interval: $119-157 \mathrm{~g} / \mathrm{L}$ ), hematocrit: $0.321 \mathrm{~L} / \mathrm{L}$ (reference interval: $0.356-0.470 \mathrm{~L} / \mathrm{L})$, total calcium $(\mathrm{Ca})$ : $1.57 \mathrm{mmol} / \mathrm{L}$ (reference interval: $2.14-2.53 \mathrm{mmol} / \mathrm{L}$ ), sodium (Na): $129 \mathrm{mmol} / \mathrm{L}$ (reference interval: $137-146 \mathrm{mmol} / \mathrm{L}$ ), potassium $(\mathrm{K}): \quad 3.4 \mathrm{mmol} / \mathrm{L}$ (reference interval: 3.9$5.1 \mathrm{mmol} / \mathrm{L}$ ), creatinine: $40 \mathrm{umol} / \mathrm{L}$ (reference interval: 49 90umol/L), total protein: $31 \mathrm{~g} / \mathrm{L}$ (reference interval: $66-81$ $\mathrm{g} / \mathrm{L}$ ), albumin: $13.2 \mathrm{~g} / \mathrm{L}$ (reference interval: $40.6-51.4 \mathrm{~g} / \mathrm{L}$ ), Creactive protein (CRP): $25.5 \mathrm{mg} / \mathrm{L}$ (reference interval: < $5 \mathrm{mg} / \mathrm{L}$ ), complement $\mathrm{C} 3: 0.51 \mathrm{~g} / \mathrm{L}$ (reference interval: 0.8 $1.6 \mathrm{~g} / \mathrm{L}$ ), complement $\mathrm{C} 4: 0.11 \mathrm{~g} / \mathrm{L}$ (reference interval: 0.16$0.48 \mathrm{~g} / \mathrm{L}$ ), CA-125: $173.2 \mathrm{KU} / \mathrm{L}$ (reference interval: < $35 \mathrm{KU} / \mathrm{L}$ ). The remaining routine laboratory tests were within their referent values.

Chest radiograph revealed prominent interstitial markings

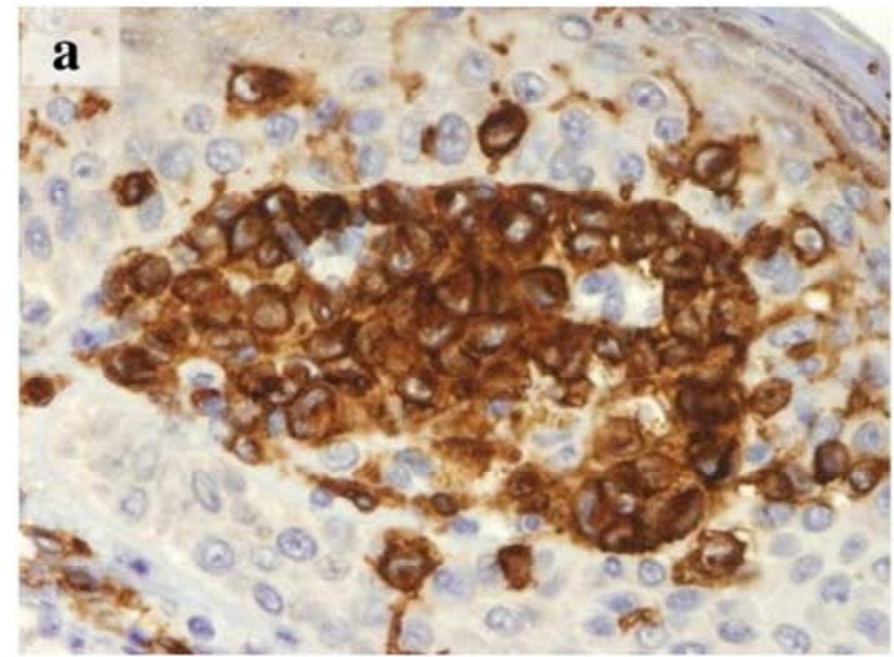

in both lungs and multi-slice computed tomography (MSCT) of the thorax showed a pathological reticular interstitial lung pattern. The patient was an ex-smoker, treated for chronic obstructive pulmonary disease (COPD) the past 3 years and struggling with persistent dermatitis-like skin lesions for the previous 5 years. During the whole previous year, before hospital admission, she suffered from abdominal disorders (malabsorption), occasional dyspnea, fever and weakness. The patient underwent a radiological, endoscopic, immunological, histopathological, and immunohistochemical processing. During further diagnostic workup, an enlarged spleen and infiltrates of Langerhans cells ( $\left.\mathrm{S}-100+, \mathrm{CD} 1 \mathrm{a}^{+}\right)$in the epidermis, intestinal mucosa and bone marrow were discovered (Figure 1 and Figure 2). In transbronchial needle biopsy of the lung, peribronchiolar and perivascular nonspecific clusters of macrophages, were found (CD68+, CD1a-). Although CD1a was negative, positive CD68, thoracic MSCT and clinical findings indicated pulmonary LCH. The patient did not accept re-needle lung biopsy or a more aggressive biopsy method.

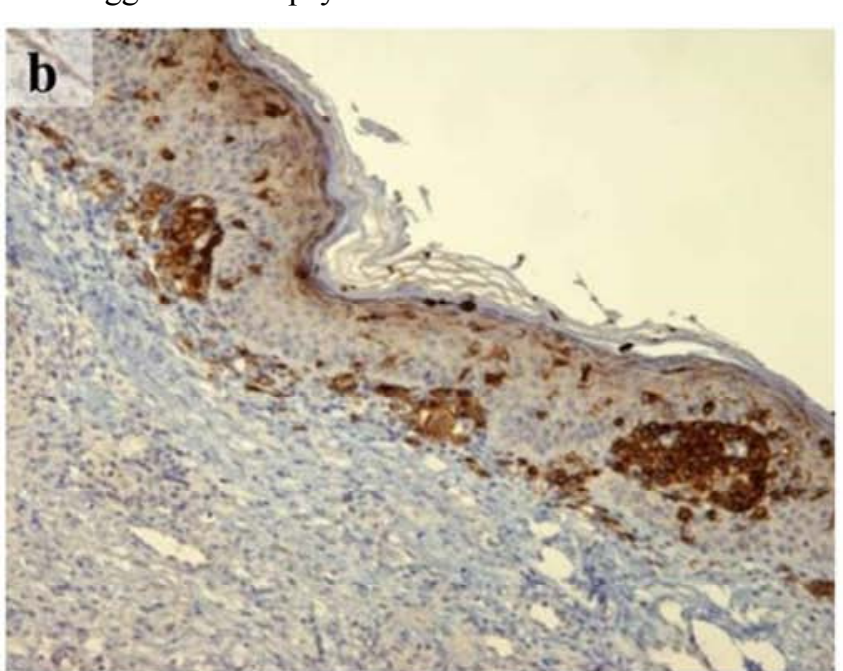

Figure 1. a, b. Bioptic material of submammary skin. Infiltrates of mononuclear cells with large, irregular nucleus, immediately under epidermis, immunohistochemically demonstrated by the expression of CDIa and S-100 antigens.
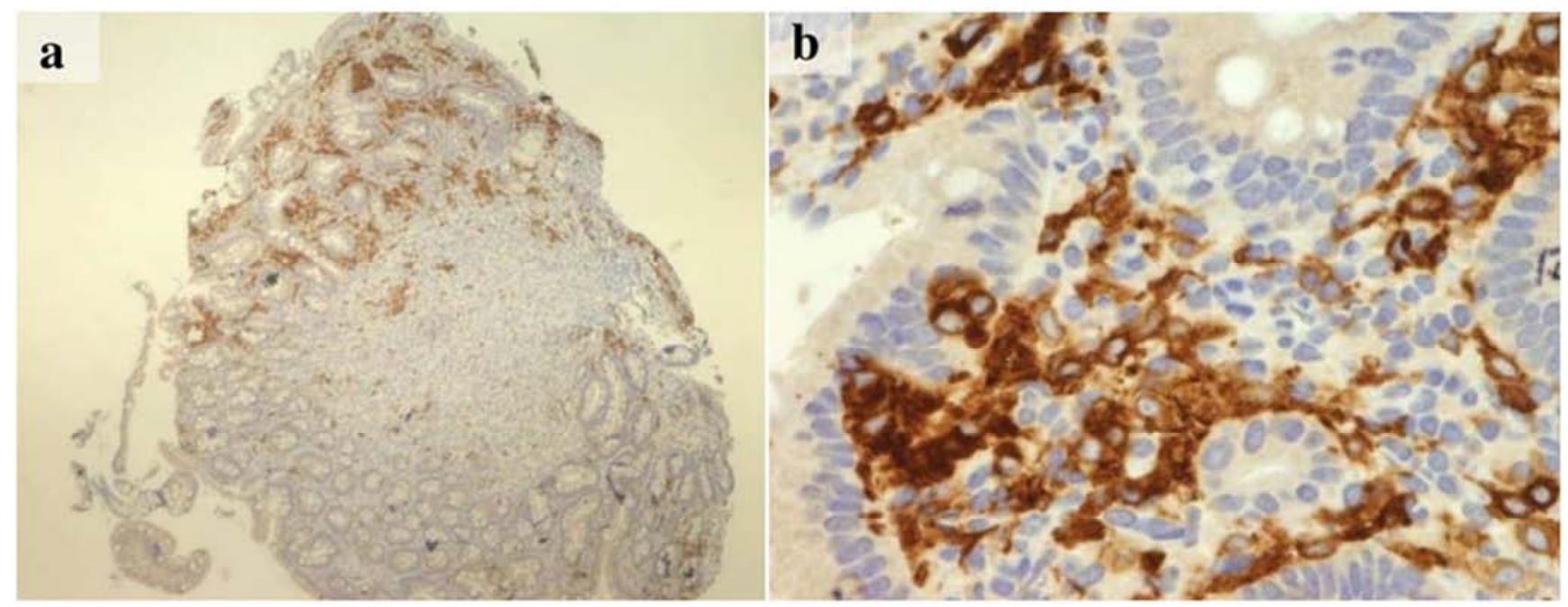

Figure 2. a, b. Bioptic material of duodenal mucosa. Collections of mononuclear cells with large, irregular nuclei (CD1a+, S-100+), and some scattered histiocytes (CD68+) are seen in lamina propria. 
Treatment with the initial dose of $0.7 \mathrm{mg} / \mathrm{kg} / \mathrm{day}$ methylprednisolone was started, leading to significant clinical improvement. The dose of methylprednisolone was gradually reduced, and the last two months was four milligrams daily. The patient did not stop smoking. Seven months after treatment with corticosteroids she developed a spontaneous left-sided pneumothorax (Figure 3). Follow up chest X-ray after a successful thoracic drainage revealed an area of left lung consolidation, with signs of cavitation (Figure 4). Thoracic HR (high resolution)-MSCT was highly suggestive for active Mycobacterium tuberculosis (MT) infection in the left lung upper lobe (Figure 5), together with the positive QUANTIFERON-TB test $\left(8.27 \mathrm{IU} \cdot \mathrm{ml}^{-1}\right)$ and typical symptoms of appetite loss, exhaustion and night sweating. Diffuse cystic nodules described in the rest of the lung parenchyma could've been a part of pulmonary LCH, however, miliary tuberculosis was also possible. One week after starting standard triple antituberculotic therapy (ATL), rifampicin $600 \mathrm{mg}$, isoniazid $400 \mathrm{mg}$ and ethambutol 1200 $\mathrm{mg}$, on a daily basis, the patient developed hypovolemic shock due to severe diarrhea, with respiratory insufficiency, hypoalbuminemia, anasarca, altered liver probes and coagulopathy. ATL therapy was interrupted after four days, and despite all medical efforts, the patient died on the thirteenth day of intensive treatment for multiple organ dysfunction syndrome. The results of bronchial aspirate cultivation on Mycobacteria Growth Indicator Tube (MGIT) and Lowenstein Jensen (LJ) culture, arrived post-mortally MT was isolated on both. An autopsy was not performed at the request of the family.

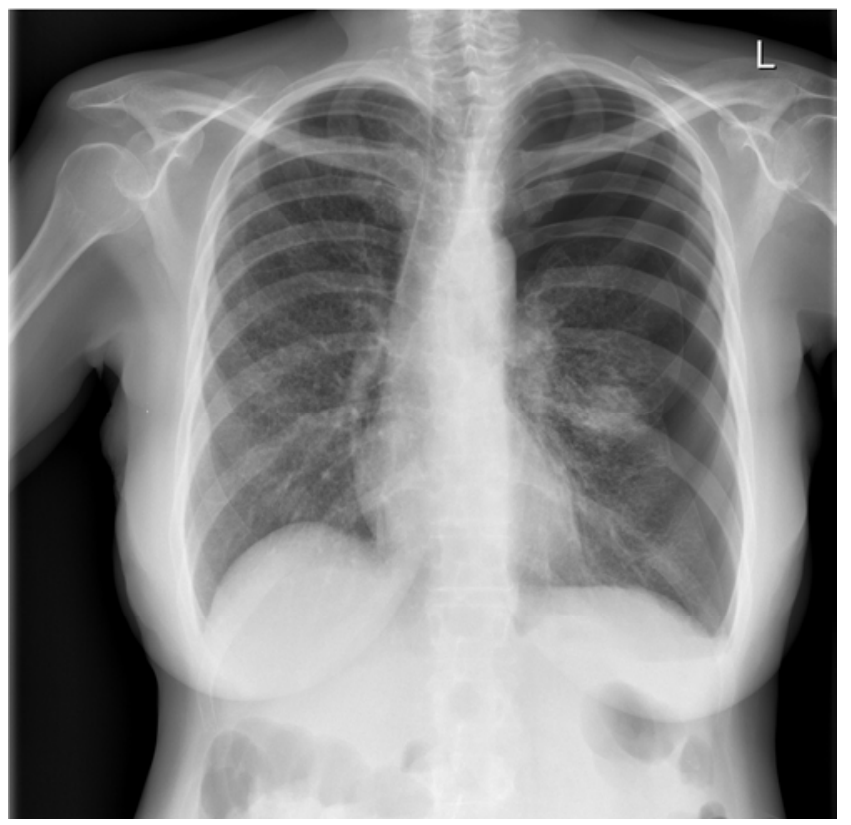

Figure 3. Chest X-ray showing a large left-sided pneumothorax.

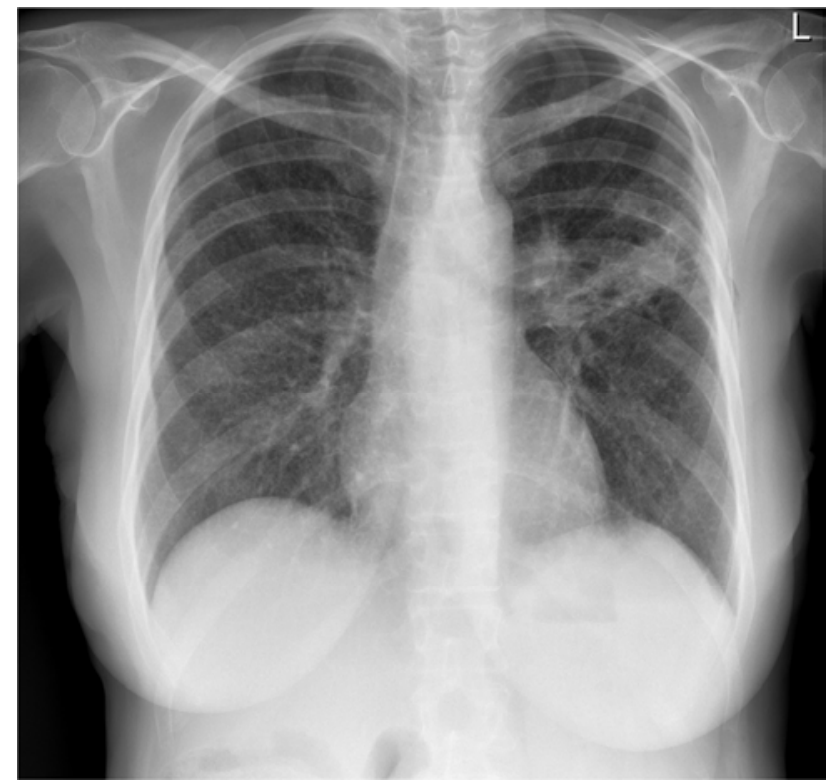

Figure 4. Post-drainage chest X-ray showing an area of left lung consolidation with signs of cavitation.

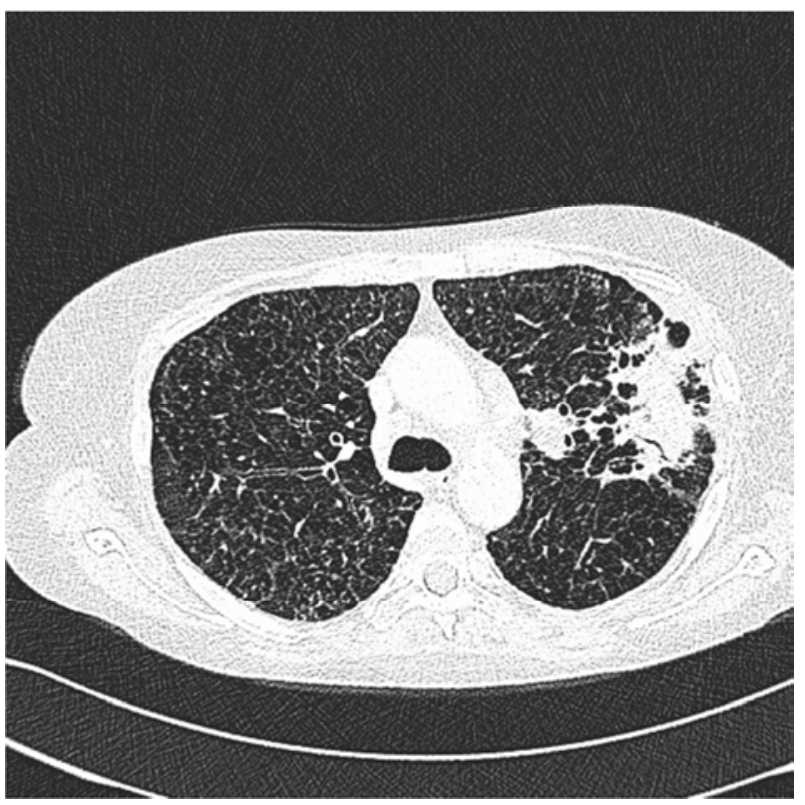

Figure 5. Thoracic HR-MSCT is highly suggestive for active pulmonary tuberculosis in the left lung upper lobe. In the rest of the lungs there are visible cystic formations typical for the $\mathrm{LCH}$.

\section{Discussion}

Langerhans cell histiocytosis is a rare disorder with estimated incidence in adults about 1-2 cases per milion. It's a little more common in children. Pulmonary LCH often mimics miliary tuberculosis [3]. It has been proven that both entities, miliary tuberculosis and pulmonary $\mathrm{LCH}$, can coexist in one patient, and that the existence of one does not exclude the other [4]. Exertional dyspnea, non-productive cough, weight loss, fever, fatigue and anorexia are the most common symptoms of pulmonary LCH, which mimic MT 
infection [5]. Some studies have confirmed that certain patients with pulmonary $\mathrm{LCH}$ and active pulmonary tuberculosis responded very well to treatment using just ATL without the use of corticosteroids [6]. On the other side, a great number of LCH diagnoses have been established, when a patient, for whom has been thought to have pulmonary tuberculosis, doesn't respond to ATL. The reason for these possible diagnostic and therapeutic errors is usually an urgency to start empirical therapy in a rapidly deteriorating patient and histomorphological similarities between epithelioid histiocytes and pathologic Langerhans cells [7]. Using radiological methods, pulmonary LCH usually presents as a pathological reticular lung pattern. However, chest x-ray can be normal and CT scan of the lung may disclose focal or diffuse abnormalities [8, 9]. Immunohistochemical reactivity for $\mathrm{CD} 1 \mathrm{a}+, \mathrm{S}-100+$ and CD68+ protein antigens, which were used in the present patient, as well as ultrastructural demonstration of Birbeck granules, present important components in confirming a final diagnosis of LCH [10]. Nearly all affected individuals with pulmonary $\mathrm{LCH}$ have a history of current or prior cigarette smoking, as well as the current patient, and it is important to note that smoking cessation alone may lead to marked improvement of the disease [11]. The present patient suffered from LCH which affected the lungs, digestive system, bone marrow and skin. After seven months of treatment with corticosteroids, pulmonary tuberculosis was established. Is lung tuberculosis a consequence of $\mathrm{LCH}$ treatment with corticosteroids (immunocompromised patient) or is it a coincidence? Although current experiences for the treatment of LCH suggest corticosteroids as a first choice of action, as was applied in this patient, there have been clinical studies that suggest corticosteroid therapy may be associated with a greater likelihood of deterioration than improvement [12]. The course of $\mathrm{LCH}$ is often difficult to predict, but in the present patient, her age, the fact that she suffered from the multi-system form of $\mathrm{LCH}$, as well as having advanced cystic changes on HRCT and an active tuberculosis infection, definitely contributed to her lethal outcome $[13,14]$.

\section{Conclusion}

In conclusion, $\mathrm{LCH}$ has various clinical manifestations which often leads to misdiagnosis or late diagnosis of this rare condition, especially in adults. The reported patient had a multy-sistem disease with the involvement of four organs, predicting poor prognosis. The patient's severe condition was further endangered with active tuberculosis infection, which consequently led to death.

\section{Compliance with Ethical Standards}

Conflicts of interest: All of the Authors declare that they have no conflict of interest.

Ethical approval: All procedures performed in studies involving human participants were in accordance with the ethical standards of the institutional and national research committee and with the 1964 Helsinki declaration and its later amendments or comparable ethical standards.
This article does not contain any studies with animals performed by any of the authors.

Informed consent: Informed consent was obtained from the participant included in the study.

\section{References}

[1] Shevale V, Ekta K, Snehal T, Geetanjal M. A rare occurrence of Langerhans cell histiocytosis in an adult. Journal of Oral and Maxillofacial Pathology. 2014; 18(3):415-9.

[2] Berres M, Merad M, Allen C. Progress in understanding the pathogenesis of Langerhans cell histiocytosis: back to Histiocytosis X? British Journal of Haematology. 2014; 169(1):3-13.

[3] Özen M, Akçakaya N, Camcioğlu Y, Cokugras H, Oz B. Isolated pulmonary Langerhans-cell histiocytosis mimicking miliary tuberculosis. J Pediatr Inf 2009; 3: 135-7.

[4] Juvet S, Hwang D, Downey G. Rare Lung Diseases III: Pulmonary Langerhans' Cell Histiocytosis. Canadian Respiratory Journal. 2010; 17(3):e55-e62.

[5] Dimitropoulos C, Vamvakaris I, Vassos D, Hamalakis G, Gkogkou C, Kokkini A, Ntanos I. Pulmonary Langerhans' cell histiocytosis or miliary tuberculosis? Case report and literature review. Arch Hell Med 2011; 28(6): 809-13.

[6] Okutan O, Kartaloglu Z, Ilvan A, Deniz O, Silit E, Gorur R. Active pulmonary tuberculosis in a patient with Langerhans cell histiocytosis. Saudi Med J 2006; 27(3):401-2.

[7] Sharma P, Dhingra K, Sural S, Mandal A, Singh T. Langerhans cell histiocytosis masquerading as tuberculosis: A diagnostic dilemma resulting in inappropriate anti-tubercular therapy. Pediatr Blood Cancer. 2009; 53(1):111-3.

[8] Zhang LMoss J. Genetic studies yield clues to the pathogenesis of Langerhans cell histiocytosis. Eur Respir J. 2016; 47(6):1629-31.

[9] Pfeifer K, Mian A, Adebowale A, Alomari A, Kalra V, Krejci E, Shin MS. Radiographic and Pathologic Manifestations of Uncommon and Rare Pulmonary Lesions. Canadian Association of Radiologists Journal. 2016; 67(2):179-89.

[10] Patne S, Dwivedi S, Katiyar R, Gupta V, Gupta A. Langerhans cell histiocytosis diagnosed by FNAC of lymph nodes. J Can Res Ther. 2015; 11(4):1028.

[11] Routy B, Hoang J, Gruber J. Pulmonary Langerhans Cell Histiocytosis with Lytic Bone Involvement in an Adult Smoker: Regression following Smoking Cessation. Case Reports in Hematology. 2015; 2015: 1-5.

[12] Watanabe R, Tatsumi K, Hashimoto S, Tamakoshi A, Kuriyama T. The Respiratory Failure Research Gr. ClinicoEpidemiological Features of Pulmonary Histiocytosis X. Intern Med. 2001; 40 (10):998-1003.

[13] Suri H, Yi E, Nowakowski G, Vassallo R. Pulmonary langerhans cell histiocytosis. Orphanet Journal of Rare Diseases. 2012; 7 (1):16.

[14] Lian C, Lu Y, Shen S. Langerhans cell histiocytosis in adults: a case report and review of the literature. Oncotarget 2016; 7 (14):18678-83. 